\title{
Editorial
}

\section{Educating Creativity}

\author{
Alessandro Antonietti ${ }^{*}$,, Barbara Colombo and Paola Pizzingrilli
}

Research Unit on Psychology of Creativity, Department of Psychology, Catholic University of the Sacred Heart-Milan, Italy

Since the 50's of the past century, the need to promote creativity in people has been stressed, and many attempts have been made to devise techniques to enhance individual and group creativity and to test the efficacy of such techniques. Educating creativity became one of the most salient goals of school instruction and of on-the-job training. The interest towards the possibility to foster creativity grew up further and nowadays it is still one of the eminent topics in education. Why is it still important to try to stimulate creativity in children and adults?

The answer should be absolutely positive, because, it is argued, habitual behaviours and thoughts may not be appropriate in a world that changes rapidly and where people have to face new challenges almost on a daily base. New answers to new questions must be rapidly found. These responses are expected to be faster and more adequate from creative individuals. Flexibility and imagination should be the qualities of the leaders of tomorrow. And, hence, school and companies will be expected to prepare persons to develop those skills. Moreover, creativity seems to be particularly necessary in times of crisis. Because of the absence of traditional resources and opportunities, escape routes - which so far were not prefigured - are needed. Thus, it is hoped that someone may devise new paths, produce new discoveries, identify new strategies which can open unexpected horizons and allow people to face difficulties and impasses, even where no way out that can apparently be seen.

A second set of reasons that justify the attention that schools and organizations should pay to creativity is as follows. Often teachers, trainers and superiors complain of poverty of ideas that, respectively, students and employees share. They lament that behaviours are conformist; that judgments are aligned to the common way of thinking and feeling, without any personal reflection. Educating creativity is proposed as an antidote to this situation. It aims to stimulate an original processing of the environmental stimuli so to overcome existing models and to explore new possibilities. Creativity challenges the individual, who is

\footnotetext{
*Address correspondence to this author at the Department of Psychology, Catholic University of Sacred Heart, Largo Gemelli, 1, 20123, Milan, Italy; Tel: +3902 7234 2909; Fax: +39 027234 2280;

E-mail: alessandro.antonietti@unicatt.it

${ }^{\S}$ Guest Editor
}

asked to ground his/her life on him/herself - on his/her beliefs, desires, dreams - and get to create something that can then be shared with others, starting from an internal and personal source. Creativity asks persons to expose and express themselves starting from what characterizes and distinguishes them. The hope is that giving the individual the opportunity to explain his/her way of seeing, thinking and acting, can help him/her to become aware of his/her potential, so to be an active agent, and not just a passive observer, of his/her world. This should hopefully be a way to gain autonomy, independence and security in life.

A third reason supporting the need to promote creativity refers to the link between creativity and well-being. It is well known that creative abilities are a powerful resource for resilience, i.e., the ability to cope with challenging situations, even dramatic, so to overcome them not only, but changing them in opportunities for development and learning. Environmental or historical circumstances of deprivation, or even more simply limitations or stressful situations, stimulate the ability to devise creative remedies and expedients or to reinterpret the current condition in a new way to "survive" despite the external adversities. The perception of being able to cope with heavy situations and being able to play an active role - the so-called sense of agency - is, in a proactive and not just reactive perspective, a component of subjective well-being. This is accompanied by perception of control, sense of autonomy, adequate selfefficacy and self-esteem, which are aspects that creativity promotes. Finally, we must not forget the motivating force that a creativity process requires, and the sensations of pleasure and satisfaction or fulfillment that exerting creativity produces, further aspects which increase wellbeing.

The aim of this special issue is to provide readers with an international and updated overview about different ways of assessing and promoting creativity in school and training settings. Such a goal has been achieved by collecting papers coming from different countries around the world. More precisely, the eleven papers included in the issue are from America (Canada), Asia (Singapore), Europe (Northern: Sweden; Central: France and Germany; Southern: Italy; Eastern: Slovenia) and Oceania (Australia).

Papers consider both individual and group creativity and cover the whole life-span perspective, by considering creativity from primary school to university students, as well as the attempts to increase creativity in adults (both 
laypeople and professionals). Conceptual frameworks, research data and interventions to stimulate creativity, which are reported in the papers, concern both general and specific forms of creativity (even with regards to specific domains).

Contributions are organized in three sections. The first section includes papers in which theoretical points of view supporting and/or inspiring the attempts to promote people's creativity are highlighted and discussed. In the first paper, John Dennis and Aldo Stella describe a possible model of the creative process based on genetic algorithms and consider the educational implications of such a model. In the second paper, Andrea Gaggioli, Luca Milani, Elvis Mazzoni and Giuseppe Riva report a model addressed to explain how creative collaboration occurs and may be enhanced. In the third paper included in this section, Norbert Jaušovec and Ksenija Jaušovec review some links between cognitive neuroscience and educational sciences. On this basis, the authors argue that cognitive neuroscience can be useful to educate creativity. After having summarized some methodological principles of cognitive neuroscience, the review focuses on the key factors linked to creativity in educational settings: intelligence, personality and learning outcomes. These aspects are also discussed in relation to some studies about the neurobiological counterparts of the effects of creativity training.

The second section includes papers where methods, techniques or procedure to measure and foster creativity are described. In the fourth article, Baptiste Barbot, Maud Besançon and Todd Lubart provide readers with an historical and systematic overview of the attempts to measure creativity and describe in detail the instrument they devised to achieve this goal. In the fifth paper, Matthew Kirby and Amedeo D'Angiulli present an analysis of the literature regarding the use of haptic in educational settings. This review brings to light the usefulness of employing haptic as an inclusive environment both for visually and non visually impaired students. The authors also reflect on how it would be possible to optimise haptic processing ability. They stress this point since it should lead to the empowerment of creativity processes. In the sixth article, Alessandro Antonietti, Barbara Colombo and Paola Pizzingrilli illustrate their own perspective on creativity, by showing how it can be assessed and fostered by means of tools which share the same basic assumptions, leading us to identify three main mental operations underlying creativity.

The third section includes papers reporting empirical data obtained through descriptive, correlational and experimental studies aimed at investigating how creative mechanisms operate and how it is possible to enhance the creative potential through relevant strategies, procedures and attitudes. Both sides of the educational process - that is, the learner's and the teacher/trainer's one - are explored. In the seventh article, Ai-Girl Tan, Joe Li and Jerome Rotgans focus on the relationship between creative self-efficacy and classroom environment. According to Amabile's componential theory, they developed a scale aimed at assessing the multidimensional concept of creativity selfefficacy (MCSE) and they tested students from different secondary schools of Shanghai. Results highlighted the positive relation between creativity self-efficacy and perceived supportive environments, thus confirming that MCSE is a good measure that predicts classroom behaviour. Moreover, this contribution supports previous findings that emphasize that creative self-efficacy may be enhanced by cohesive and cooperative classroom atmosphere and by teacher supported behaviour. In the eighth paper, Howard Middleton and John Stevenson take into account a specific topic linked to creativity training which is not frequently addressed in the literature: creativity in technical and vocational education. The topic is addressed starting from a literature analysis and then contextualized with respect to two empirical studies, aimed at testing the theoretical principles set out by the authors. The implications derived from these studies, together with general considerations for future and wider applications, are discussed. The ninth paper, by Detlef Urhahne and Dagiadi Alcazar Ortiz, shifts attention to the differences between gifted and regular students of German secondary schools in creative performances in poetry and arts. In particular, the authors investigated whether gifted students show different motivations and emotions when they are involved in a creative task. Results revealed that students with extraordinary talent attribute specific characteristics to the creative task, by conceiving it as challenging and as an achievement opportunity in which people can activate their own creative competencies. Moreover, gifted students experience higher motivation for the creative task and show higher creativity self-efficacy than average-ability students. In the tenth article, Ulrike Hanke, Dirk Ifenthaler and Norbert Seel move toward the other side of creativity education, namely, teaching, and tested the hypothesis that personal dispositions toward creativity modulate the way in which teaching activities are designed. In the last article, Eva Hoff and Ingegerd Carlsson analyze how Swedish teachers evaluate creativity in their students. They compared the results from creativity tests with school children's selfdescriptions and teachers' ratings of creativity. The low association between objective creativity tests and teachers' evaluations confirms the need to devise specific training for teachers in order to fill the scarcity of knowledge about creativity and to favour divergent thinking in the classroom.

(C) Antonietti et al.; Licensee Bentham Open.

This is an open access article licensed under the terms of the Creative Commons Attribution Non-Commercial License (http://creativecommons.org/licenses/by-nc/ 3.0/) which permits unrestricted, non-commercial use, distribution and reproduction in any medium, provided the work is properly cited. 